\title{
Infinite Dilution Activity Coefficients in the Smectic and Isotropic Phases of Tetrafluoroborate-Based Ionic Liquids
}

\author{
Mónia A. R. Martins, Sérgio M. Vilas-Boas, Isabella Weber Cordova, Pedro J. Carvalho, \\ Urszula Domańska, Olga Ferreira, João A. P. Coutinho, and Simão P. Pinho*
}

Cite This: J. Chem. Eng. Data 2021, 66, 2587-2596

Read Online

ACCESS |

山ll Metrics \& More

回 Article Recommendations

S1 Supporting Information

ABSTRACT: Inverse gas chromatography was used to obtain the activity coefficients at infinite dilution $\left(\gamma_{13}^{\infty}\right)$ of several organic solutes and water in the thermotropic ionic liquid crystal phases of both $\left[\mathrm{C}_{12} \mathrm{mim}\right]\left[\mathrm{BF}_{4}\right]$ and $\left[\mathrm{C}_{14} \mathrm{mim}\right]\left[\mathrm{BF}_{4}\right]$ and their isotropic phases. In the smectic to isotropic transition, a change in the linear representation of the natural logarithm of $\gamma_{13}^{\infty}$ with the reciprocal temperature was observed for $\left[\mathrm{C}_{14} \mathrm{mim}\right]\left[\mathrm{BF}_{4}\right]$, and was more evident for alkanes, alkylbenzenes, esters, and alcohols, that can be related to structural modifications of the stationary phase. Results are interpreted in terms of the enthalpic and entropic contributions of solute-IL interactions. Selectivities and capacities of important separation problems, such as octane/benzene and cyclohexane/

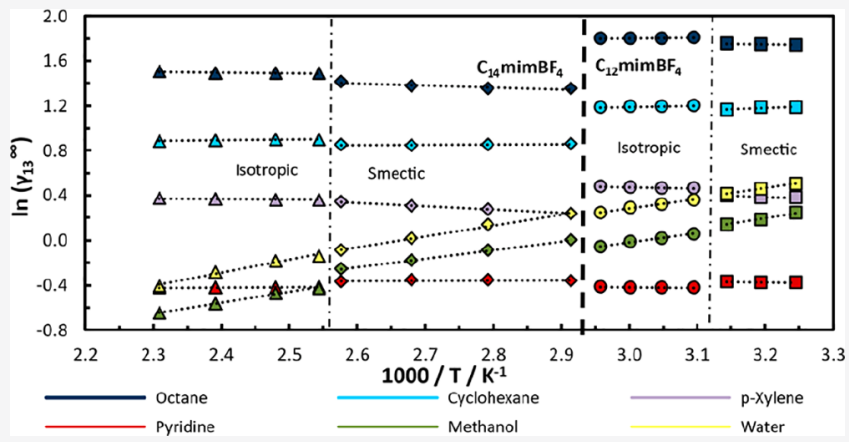
benzene, were calculated and compared with literature values for separating agents such as $N$-methyl-2-pyrrolidinone, sulfolane, and ionic liquids presenting the $\left[\mathrm{BF}_{4}\right]^{-}$anion combined with several imidazolium-based cations. It is shown that to achieve maximum separation efficiency, imidazolium cations with short alkyl chain lengths such as $\left[\mathrm{C}_{2} \mathrm{mim}\right]\left[\mathrm{BF}_{4}\right]$ should be used, whereas high capacities require larger alkyl chain lengths.

\section{INTRODUCTION}

Ionic liquids (ILs) are complex substances usually comprising bulky organic cations coupled with organic or inorganic anions. ${ }^{1}$ Due to their microphase-separated structures, ILs can exhibit mesomorphic behavior, the so-called IL crystals (ILCs). ${ }^{2}$ These ordered liquid-crystalline forms, where the main structural units are mesogenic ions stabilized by electrostatic forces acting between them, combine the ionic character of ILs with the liquid crystals' anisotropy.,

ILCs have been widely studied and were identified as promising candidates to design anisotropic ion-conductive materials for molecular electronics, batteries, fuel cells, and capacitors as a tool to improve the efficiency of dye-sensitized solar cells and as electrochromic materials. ${ }^{4,5}$ Their anisotropic character also suggests their use as ordered solvents or organized reaction media in different applications. ${ }^{4,6}$

To further exploit the ILs' potential as separation agents, their interactions with several organic solutes and water can be evaluated by determining the activity coefficients at infinite dilution $\left(\gamma_{13}^{\infty}\right)$ of each solute (component 1 ) in the IL (component 3 ). These, together with the derived thermodynamic properties, allow us to explore both the effects of the solute and solvent structures on the solvation process.

To the best of our knowledge, there are no studies on $\gamma_{13}^{\infty}$ in ILCs. However, some studies address the $\gamma_{13}^{\infty}$ of organic solutes in liquid crystalline solvents, aiming to investigate the interaction of the solutes with the liquid crystal mesophases. $^{7-11}$ Oweimreen ${ }^{8}$ and Gidley and Stubley ${ }^{9}$ investigated the activity coefficients at infinite dilution of various solutes in the nematic and isotropic phases of different liquid crystals. Gidley and Stubley ${ }^{9}$ used the $\gamma_{13}^{\infty}$ to determine the limiting behaviors of the two-phase region of the phase diagram at infinite dilution, while Oweimreen ${ }^{8}$ demonstrated the effect of the solute molecular size, shape, flexibility, polarizability, and polarity on the solution process. More recently, Oweimreen ${ }^{12}$ used the $\gamma_{13}^{\infty}$ to investigate the solubility of several solutes in the smectic, nematic, and isotropic phases of $p$-n-octyl- $p^{\prime}$ cyanobiphenyl.

In this work, the $\gamma_{13}^{\infty}$ of alkanes, cycloalkanes, ketones, ethers, aromatic hydrocarbons, esters, alcohols, acetonitrile, pyridine, thiophene, and water in the ILCs 1-dodecyl-3-methylimidazolium tetrafluoroborate $\left(\left[\mathrm{C}_{12} \mathrm{mim}\right]\left[\mathrm{BF}_{4}\right]\right)$ or 1-tetradecyl-3methylimidazoliumtetrafluoroborate $\left(\left[\mathrm{C}_{14} \mathrm{mim}\right]\left[\mathrm{BF}_{4}\right]\right)$ in both liquid and crystal liquid phases are reported. ILs with the same anion and different cations were chosen to

Received: March 8, 2021

Accepted: April 30, 2021

Published: May 13, 2021 
Table 1. Chemical Name, Structure, Supplier, and Mass Fraction Purity of the Organic Solutes Used

\begin{tabular}{|c|c|c|c|c|}
\hline & chemicals $^{a}$ & CAS & supplier & mass fraction purity ${ }^{b}$ \\
\hline \multirow[t]{3}{*}{ alkanes } & octane & $111-65-9$ & Aldrich & $\geq 0.990$ \\
\hline & nonane & $111-84-2$ & Aldrich & $\geq 0.990$ \\
\hline & decane & $124-18-5$ & Aldrich & $\geq 0.990$ \\
\hline \multirow[t]{2}{*}{ cyclic alkanes } & cyclohexane & $110-82-7$ & Aldrich & $\geq 0.990$ \\
\hline & methylcyclohexane & $108-87-2$ & Aldrich & $\geq 0.990$ \\
\hline \multirow[t]{2}{*}{ ketones } & propan-2-one (acetone) & $67-64-1$ & Aldrich & $\geq 0.999$ \\
\hline & butan-2-one & $78-93-3$ & Aldrich & $\geq 0.990$ \\
\hline ethers & ethoxyethane (diethyl ether) & $60-29-7$ & Aldrich & $\geq 0.999$ \\
\hline \multirow[t]{2}{*}{ cyclic ethers } & oxolane (THF) & $109-99-9$ & Aldrich & $\geq 0.999$ \\
\hline & 1,4-dioxane & $123-91-1$ & Aldrich & $\geq 0.998$ \\
\hline \multirow[t]{4}{*}{ aromatic hydrocarbons } & benzene & $71-43-2$ & Aldrich & $\geq 0.998$ \\
\hline & toluene & $108-88-3$ & Aldrich & $\geq 0.998$ \\
\hline & ethylbenzene & $100-41-4$ & Aldrich & $\geq 0.998$ \\
\hline & $p$-xylene & $106-42-3$ & Aldrich & $\geq 0.990$ \\
\hline \multirow[t]{3}{*}{ esters } & methyl acetate & $79-20-9$ & Aldrich & $\geq 0.998$ \\
\hline & ethyl acetate & $141-78-6$ & Aldrich & $\geq 0.998$ \\
\hline & vinyl acetate & $108-05-4$ & Aldrich & $\geq 0.990$ \\
\hline \multirow[t]{11}{*}{ alcohols } & methanol & $67-56-1$ & Aldrich & $\geq 0.999$ \\
\hline & ethanol & $64-17-5$ & Aldrich & $\geq 0.998$ \\
\hline & propan-1-ol & $71-23-8$ & Aldrich & $\geq 0.999$ \\
\hline & propan-2-ol & $67-63-0$ & Fluka & $\geq 0.999$ \\
\hline & butan-1-ol & $71-36-3$ & Aldrich & $\geq 0.998$ \\
\hline & butan-2-ol & $78-92-2$ & Aldrich & $\geq 0.995$ \\
\hline & 2-methyl-propan-1-ol & $78-83-1$ & Aldrich & $\geq 0.995$ \\
\hline & 2-methyl-propan-2-ol (tert-butanol) & $75-65-0$ & Aldrich & $\geq 0.997$ \\
\hline & acetonitrile & $75-05-8$ & Fluka & $\geq 0.999$ \\
\hline & pyridine & $110-86-1$ & Aldrich & $\geq 0.998$ \\
\hline & thiophene & $110-02-1$ & Aldrich & $\geq 0.990$ \\
\hline \multirow[t]{2}{*}{ ILs } & 1-dodecyl-3-methylimidazolium tetrafluoroborate $\left(\left[\mathrm{C}_{12} \mathrm{mim}\right]\left[\mathrm{BF}_{4}\right]\right)$ & $244193-59-7$ & Iolitec & $\geq 0.980$ \\
\hline & 1-tetradecyl-3-methylimidazolium tetrafluoroborate $\left(\left[\mathrm{C}_{14} \mathrm{mim}\right]\left[\mathrm{BF}_{4}\right]\right)$ & $244193-61-1$ & Iolitec & $\geq 0.980$ \\
\hline
\end{tabular}

understand the influence of the liquid crystal structure on the $\gamma_{13}^{\infty}$. These coefficients were calculated from the measured retention times obtained by gas-liquid chromatography (GLC) in the temperature ranges (308.15-338.15) $\mathrm{K}$ for $\left[\mathrm{C}_{12} \mathrm{mim}\right]\left[\mathrm{BF}_{4}\right]$ and $(343.15-433.15) \mathrm{K}$ for $\left[\mathrm{C}_{14} \mathrm{mim}\right]\left[\mathrm{BF}_{4}\right]$, covering the two different phase forms.

\section{EXPERIMENTAL SECTION}

2.1. Chemicals. The chemical names, CAS, sources, and mass purities of the organic solutes and ILs used in this work are presented in Table 1 . The organic solutes were used as received. The ILs were dried under vacuum at $0.1 \mathrm{~Pa}$ and $353.15 \mathrm{~K}$ under constant stirring and for a minimum period of $48 \mathrm{~h}$. Additional volatile impurities and traces of water were removed during the column preconditioning at high temperatures. The water used was distilled and filtered, presenting a final mass fraction purity higher than $99.9 \%$.

2.2. Experimental Procedure. 2.2.1. Differential Scanning Calorimetry. The phase transition temperatures of $\left[\mathrm{C}_{12} \mathrm{mim}\right]\left[\mathrm{BF}_{4}\right]$ were reported by us before. ${ }^{13}$ The same procedure was applied here for $\left[\mathrm{C}_{14} \mathrm{mim}\right]\left[\mathrm{BF}_{4}\right]$ using a Hitachi DSC7000X, working at atmospheric pressure. Samples of approximately $(2-6) \mathrm{mg}$ tightly sealed in aluminum pans were submitted to three repeated heating-cooling cycles at 2 and 5 $\mathrm{K} \cdot \mathrm{min}^{-1}$, respectively. To avoid water condensation inside the oven at low temperatures, a constant nitrogen flow of $50 \mathrm{~cm}^{3}$. $\min ^{-1}$ was supplied to the differential scanning calorimetry (DSC) cell. The temperatures of the thermal transitions were analyzed in the several heating runs and taken as the peak temperature. The first cycle allowed sample homogenization inside the pan and, thus, was not considered. The temperature uncertainty calculated through the average of the standard deviation of several consecutive measurements was better than $\pm 0.1 \mathrm{~K}$. The equipment was previously calibrated with anthracene, benzoic acid, caffeine, decane, diphenylacetic acid, heptane, indium, lead, naphthalene, 4-nitrotoluene, potassium nitrate, tin, water, and zinc, all with weight fraction purities higher than $99 \%$.

2.2.2. Activity Coefficients at Infinite Dilution Measurements. The experimental procedure, including the column preparation and packing method, were already detailed in our previous works. ${ }^{14-17}$ Briefly, columns made of glass with $1 \mathrm{~m}$ length and $4 \mathrm{~mm}$ internal diameter were used. The filling was prepared by coating $45-50 \%$ IL stationary phase onto $80 / 100$ mesh Chromosorb W/AW-DMCS support material supplied by GRACE. To ensure a uniform coating, methanol was used as the solvent and later evaporated under vacuum until the final and original masses of the IL and Chromosorb were in agreement within $\pm 1 \times 10^{-4} \mathrm{~g}$. The columns were placed into a Varian 3380 gas chromatograph equipped with an on-column injector and a thermal conductivity detector and left for equilibration inside the chromatograph at $393.15 \mathrm{~K}$ for at least $6 \mathrm{~h}$. During the experiments, the injector and detector temperatures were maintained at 473.15 and $523.15 \mathrm{~K}$, respectively, and helium was used as the carrier gas. Exit gas flow rates, the outlet pressure, and the temperature were 
Table 2. Phase Transition Temperatures and Enthalpies of $\left[\mathrm{C}_{12} \mathrm{mim}\right]\left[\mathrm{BF}_{4}\right]$ and $\left[\mathrm{C}_{14} \mathrm{mim}\right]\left[\mathrm{BF}_{4}\right]$ at $p=93.8 \mathrm{kPa}\left(u_{\mathrm{r}}=0.05\right)$, along with Literature Data ${ }^{a}$

\begin{tabular}{|c|c|c|c|c|}
\hline & \multicolumn{2}{|c|}{ solid $\rightarrow$ liquid crystal } & \multicolumn{2}{|c|}{ liquid crystal $\rightarrow$ liquid } \\
\hline & heating & cooling & heating & cooling \\
\hline \multicolumn{5}{|c|}{$\left[\mathrm{C}_{12} \mathrm{mim}\right]\left[\mathrm{BF}_{4}\right]$} \\
\hline \multirow[t]{3}{*}{$T / \mathrm{K}$} & $302.94 \pm 1.87^{13}$ & $286.15 \pm 1.39^{13}$ & $320.20 \pm 0.27^{13}$ & $319.67 \pm 0.16^{13}$ \\
\hline & $302.65^{25 b}$ & $273.15^{25}$ & $324.75^{25 b}$ & $324.15^{25}$ \\
\hline & $300.15^{25 c}$ & & $325.15^{25}$, & \\
\hline$\Delta$ Htrans $/ \mathrm{kJ} \cdot \mathrm{mol}-1$ & $27.05 \pm 2.81$ & $\begin{array}{c}26.26 \pm 3.40 \\
{\left[\mathrm{C}_{14} \mathrm{mim}\right]\left[\mathrm{BF}_{4}\right]}\end{array}$ & $0.30 \pm 0.03$ & $0.31 \pm 0.03$ \\
\hline$T / \mathrm{K}$ & $296.00(1.46)^{d}$ & & & \\
\hline $315.55^{24}$ & $292.79(1.86)^{d}$ & & & \\
\hline $302.45^{24}$ & & $385.43(3.97)^{d}$ & & \\
\hline $402.65^{24}$ & $384.02(3.20)^{d}$ & & & \\
\hline \multicolumn{5}{|l|}{$403.15^{24}$} \\
\hline & $317.15^{25}$ & $298.25^{25}$ & $398.55^{25}$ & $397.05^{25}$ \\
\hline$\Delta H_{\text {trans } /} \mathrm{kJ} \cdot \mathrm{mol}^{-1}$ & $20.09(5.22)^{d}$ & & & \\
\hline $20.7^{24}$ & $21.36(2.09)^{d}$ & & & \\
\hline $16.8^{24}$ & & $0.80(0.52)^{d}$ & & \\
\hline $0.6^{24}$ & $0.67(0.25)^{d}$ & & & \\
\hline $0.6^{24}$ & & & & \\
\hline
\end{tabular}

${ }^{a}$ Whenever available, the standard deviation is placed after plus-minus sign. ${ }^{b}$ The transition temperature was registered in the first DSC heating cycle. ${ }^{c}$ The transition temperature was registered in the second DSC heating cycle. ${ }^{d}$ Expanded uncertainty at $95 \%$ confidence level.

measured with an Agilent Precision gas flow meter (with repeatability of $\pm 0.2 \%$ full Scale). For each IL, at least two columns with different packing percentages were prepared. The different solutes were injected at infinite dilution $(0.1-0.3$ $\mu \mathrm{L}$ ) along with air, the non-retained component. Retention times were calculated by the difference of the retention times of the solute, $t_{\mathrm{R}}$, and air, $t_{\mathrm{G}}$. Each experiment was repeated at least twice to check the reproducibility.

2.3. Theoretical Background. When an infinitesimal amount of solute sample is introduced into a column with a nonvolatile stationary phase, it is possible to calculate the $\gamma_{13}^{\infty}$ for the solute (1) partitioning between the carrier gas (2) and the nonvolatile compound (3). Moreover, aiming the determination of the order of elution from columns, partition coefficients are also extracted from the retention data. The gas-liquid partition coefficients, $K_{\mathrm{L}}$, are useful to understand the extraction process and the recovery of the extractive agent at low pressure.

2.3.1. Activity Coefficients at Infinite Dilution. The net retention volume of the solute, $V_{\mathrm{N}},{ }^{18}$ and the pressure correction term, $J_{2}^{3}$, ${ }^{19}$ were calculated with the following usual relationships

$$
\begin{aligned}
& V_{\mathrm{N}}=\left(J_{2}^{3}\right)^{-1} U_{\mathrm{f}} \frac{P_{\mathrm{f}}}{P_{0}} \frac{T}{T_{\mathrm{f}}}\left(t_{\mathrm{R}}-t_{\mathrm{G}}\right) \\
& J_{2}^{3}=\frac{2}{3} \frac{\left(P_{i} / P_{0}\right)^{3}-1}{\left(P_{i} / P_{0}\right)^{2}-1}
\end{aligned}
$$

where $U_{\mathrm{f}}$ is the volumetric flow rate measured at the outlet of the column, $P_{\mathrm{f}}$ and $T_{\mathrm{f}}$ are, respectively, the gas outlet pressure and temperature (measured by the flowmeter), $P_{0}$ is the column outlet pressure, $T$ is the oven temperature, $t_{\mathrm{R}}$ is the solute retention time, while $t_{\mathrm{G}}$ is the same for air, and $P_{i}$ is the inlet pressure.

The activity coefficients at infinite dilution of a solute (1) in the ILCs (3) were calculated through the equation developed by Everett ${ }^{19}$ and Cruickshank et al. ${ }^{20}$

$$
\ln \gamma_{13}^{\infty}=\ln \left(\frac{n_{3} R T}{V_{\mathrm{N}} P_{1}^{*}}\right)-\frac{P_{1}^{*}\left(B_{11}-V_{1}^{*}\right)}{R T}+\frac{P_{0} J_{2}^{3}\left(2 B_{12}-V_{1}^{\infty}\right)}{R T}
$$

where $R$ is the ideal gas constant, $n_{3}$ is the number of moles of solvent on the column packing, $P_{1}^{*}$ is the saturated vapor pressure of the solute, $B_{11}$ is the second virial coefficient of the pure solute, $V_{1}^{*}$ is the molar volume of the solute, $B_{12}$ is the crossed second virial coefficient of the solute and the carrier gas (helium), and $V_{1}^{\infty}$ is the partial molar volume of the solute at infinite dilution in the solvent. The temperature-dependent properties were calculated at $T$ using equations and constants taken from the literature. ${ }^{21,22}$

As the activity coefficients at infinite dilution were determined as a function of temperature, the enthalpic $\left(\bar{H}_{\mathrm{m}}^{\mathrm{E}, \infty}\right)$ and entropic $\left(\bar{S}_{\mathrm{m}}^{\mathrm{E}, \infty}\right)$ contributions to the excess Gibbs energy $\left(\bar{G}_{\mathrm{m}}^{\mathrm{E}, \infty}\right)$ can be determined at infinite dilution using the following equations

$$
\begin{aligned}
& \bar{G}_{\mathrm{m}}^{\mathrm{E}, \infty}=R T \ln \left(\gamma_{13}^{\infty}\right) \\
& \bar{H}_{\mathrm{m}}^{\mathrm{E}, \infty}=R\left(\frac{\partial \ln \gamma_{13}^{\infty}}{\partial \ln (1 / T)}\right)_{p, \underline{x}} \\
& \bar{S}_{\mathrm{m}}^{\mathrm{E}, \infty}=\frac{\bar{H}_{\mathrm{m}}^{\mathrm{E}, \infty}-\bar{G}_{\mathrm{m}}^{\mathrm{E}, \infty}}{T}
\end{aligned}
$$

where subscripts $p$ and $x$ indicate isobaric and constant composition conditions, respectively.

Moreover, $\gamma_{13}^{\infty}$ data is essential in the selection of a suitable entrainer for a given separation problem as it allows the calculation of the selectivity between the solutes $i$ and $j, S_{i j}^{\infty}=$ $\gamma_{i}^{\infty} / \gamma_{j}^{\infty}$, and the capacity, $k_{j}^{\infty}=1 / \gamma_{j}^{\infty}$, of the separation process $^{23}$ ( $j$ is the solute that presents the smaller $\gamma_{13}^{\infty}$ in the solvent).

2.3.2. Gas-Liquid Partition Coefficients. The gas-liquid partition coefficients $K_{\mathrm{L}}=\left(c_{1}^{\mathrm{L}} / c_{1}^{\mathrm{G}}\right)$ for a solute partitioning 


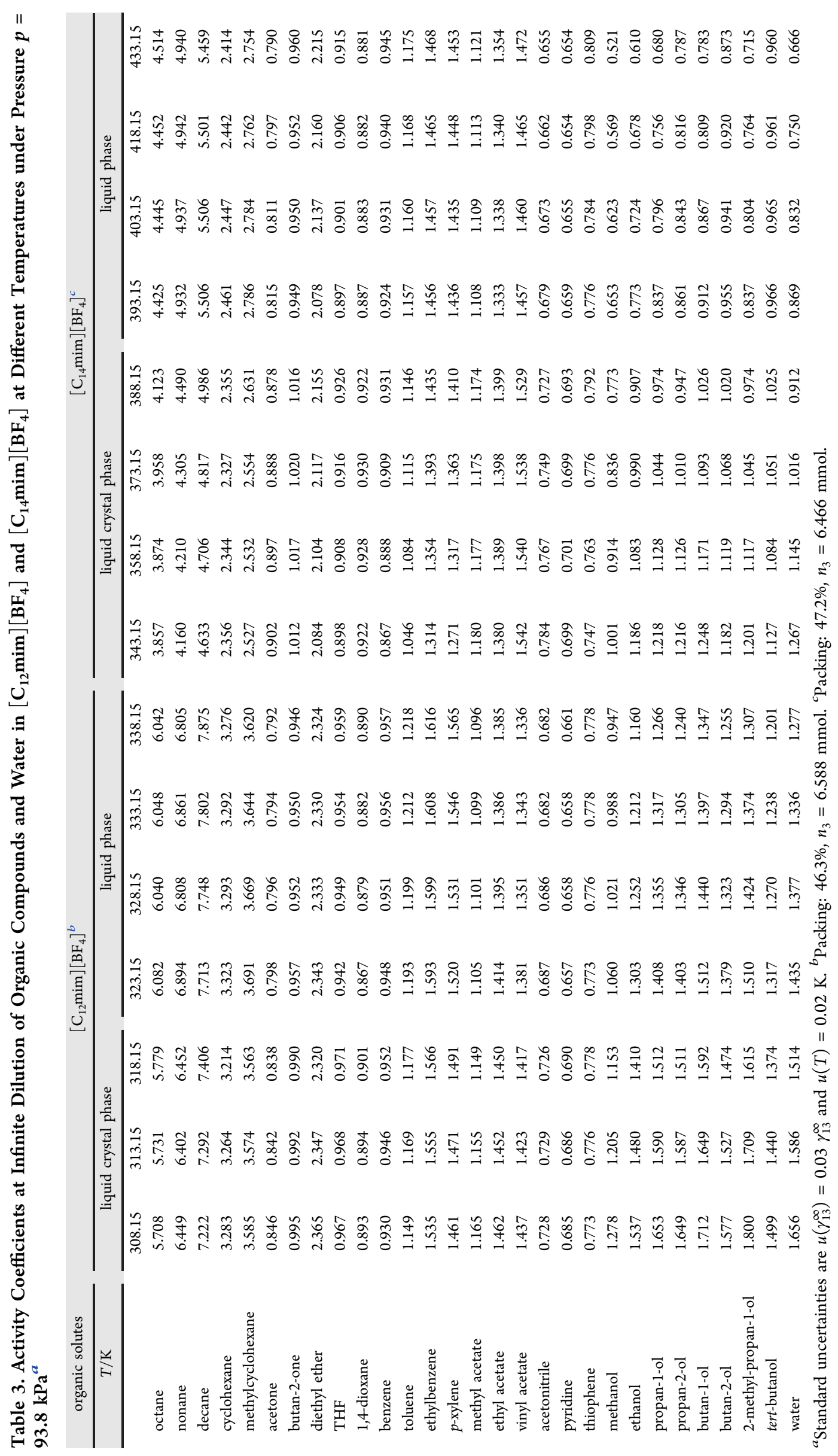


between the carrier gas (helium) and the ILs were calculated from the solute retention according to

$$
\ln \left(K_{\mathrm{L}}\right)=\ln \left(\frac{V_{\mathrm{N}} \rho_{3}}{m_{3}}\right)-\frac{P_{0} J_{2}^{3}\left(2 B_{12}-V_{1}^{\infty}\right)}{R T}
$$

in which $\rho_{3}$ and $m_{3}$ are the density and the mass of the IL, respectively.

\section{RESULTS AND DISCUSSION}

3.1. Differential Scanning Calorimetry. The solid $\rightarrow$ liquid crystal $\rightarrow$ liquid phase transitions (and respective melting and clearing points) of the $\left[\mathrm{C}_{14} \mathrm{mim}\right]\left[\mathrm{BF}_{4}\right]$ IL were examined by DSC, and the results are presented in Table 2 together with the data obtained by Holbrey and Seddon ${ }^{24}$ and Nozaki et al. ${ }^{25}$ An exemplificative DSC thermogram displaying the phase behavior of $\left[\mathrm{C}_{14} \mathrm{mim}\right]\left[\mathrm{BF}_{4}\right]$ investigated in this work is shown in Figure S1 of the Supporting Information. Evident differences can be observed between the experimental values measured in this work and the literature data. However, one should take into account factors such as purity, water content, and heating rates. The phase transition temperatures of $\left[\mathrm{C}_{12} \mathrm{mim}\right]\left[\mathrm{BF}_{4}\right]$ reported by us before ${ }^{13}$ are also displayed along with the data reported by Nozaki and co-authors. ${ }^{25}$ Both compounds are characterized by a large enthalpy for the solid $\rightarrow$ liquid crystal phase transition, suggesting a significant structural change and a small enthalpy for the smectic $\rightarrow$ isotropic mesophases transition due to the reorganization of the alkyl chains at the clearing point. ${ }^{24}$ Additionally, they are characterized by a supercooling region before crystallization that can also manifest in hysteresis around the clarification or cooling. ${ }^{11}$ However, the supercooled region of both ILs studied here was sufficiently large and stable for reproducible measurements to be made.

3.2. Activity Coefficients at Infinite Dilution. The activity coefficients at infinite dilution of 28 organic solutes and water in the ILs $\left[\mathrm{C}_{12} \mathrm{mim}\right]\left[\mathrm{BF}_{4}\right]$ and $\left[\mathrm{C}_{14} \mathrm{mim}\right]\left[\mathrm{BF}_{4}\right]$, at several temperatures, are listed in Table 3. Temperatures were chosen based on the transition liquid crystal $\rightarrow$ liquid (clarification temperature) measured by us in order to understand eventual differences in the $\gamma_{13}^{\infty}$ and their derived properties between the two phases, liquid crystal and isotropic liquid. At least three different temperatures were chosen before and after the transition, with intervals of 5 to $15 \mathrm{~K}$ for $\left[\mathrm{C}_{12} \mathrm{mim}\right]\left[\mathrm{BF}_{4}\right]$ and $\left[\mathrm{C}_{14} \mathrm{mim}\right]\left[\mathrm{BF}_{4}\right]$, respectively. Deviations on the $\gamma_{13}^{\infty}$ in the different columns show repeatability within $\pm 1.5 \%$ for the vast majority of the solutes. The estimated overall error in the $\gamma_{13}^{\infty}$ was less than $3 \%$, taking into account the solute retention time accuracy $(0.001 \mathrm{~min})$ and the standard deviations (in parentheses) related to solute vapor pressures $(<5 \%)$, mass of the stationary phase $\left(<1 \times 10^{-4} \mathrm{~g}\right)$, flow rate of helium $\left(0.1 \mathrm{~cm}^{3} \cdot \mathrm{min}^{-1}\right)$, inlet $(0.1 \mathrm{kPa})$ and outlet $(0.07 \mathrm{kPa})$ pressures, and oven temperature $(0.1 \mathrm{~K})$.

The nonvolatile liquid solvents evaluated in this work are thermotropic, that is, compounds that form a mesophase upon heating the solid state or upon cooling the isotropic liquid, and the $\gamma_{13}^{\infty}$ temperature dependence is presented in Figures S2 and S3 of the Supporting Information. When the stationary phase is in the same aggregation state, a linear behavior in the natural logarithm of $\gamma_{13}^{\infty}$ with the reciprocal temperature is observed. Generally, for alcohols and water, $\gamma_{13}^{\infty}$ decreases with increasing temperature, while the opposite is observed for most of the other solutes. Even considering the low basicity of anion
$\left[\mathrm{BF}_{4}\right]^{-26}$ the interactions between the IL and alcohols, or water, are in part attributed to hydrogen bonding. The intensity of these interactions diminishes with the temperature increase, which should result in higher activity coefficients. The decrease of the activity coefficients observed for alcohols, and water, with the temperature, also observed by other researchers with the same type of $\mathrm{IL}^{27}$ suggests significant and favorable entropic effects.

When measuring the molecular diffusion coefficients of four solutes in a $60 \mathrm{~K}$ temperature interval, Gritti et al. ${ }^{28}$ observed a transition domain separating two different temperature dependences of that property in the nematic and isotropic phases, which was attributed to the structural changes in the studied liquid crystalline polymers. ${ }^{28}$ Observing Figures S2 and $\mathrm{S} 3$, while for $\left[\mathrm{C}_{12} \mathrm{mim}\right]\left[\mathrm{BF}_{4}\right]$, the temperature range is very narrow for any substantial conclusion, a much more visible trend shift between 388.15 and $393.15 \mathrm{~K}$, corresponding to the temperature of clarification, is observed for $\left[\mathrm{C}_{14} \mathrm{mim}\right]\left[\mathrm{BF}_{4}\right]$. The agreement between the transition temperatures measured by calorimetry and the mentioned trend shift demonstrates that the absorption of the solute (at infinite dilution) does not eliminate the differences in the IL behavior concerning the stationary phase. Several authors ${ }^{7,9,11,28-30}$ observed slope changes while measuring the activity coefficients of infinitely dilute solutions or diffusion coefficients of organic solvents in liquid crystals and attributed them to the existence of different phases. However, as discussed in the next section, the changes in the derived excess properties are, in this work, more evident for some particular chemical families.

In general, the measured $\gamma_{13}^{\infty}$ were greater than unity, indicating that the ILs are unfavorable solvents for the solutes investigated. Less polar solutes, alkanes, present the poorest interactions (higher infinite dilution activity coefficients) with the ILs studied, as previously reported for other ILs. ${ }^{15}$ It has been demonstrated that the cation plays a major role in the solvation process, ${ }^{31}$ and the fact that the aliphatic solutes show smaller retention times indicates their weak interaction with the alkyl tail of the cation. On the other hand, polar aprotic solutes, such as acetone, tetrahydrofuran (THF), 1,4-dioxane, and more evidently thiophene, pyridine, and acetonitrile, present the lowest $\gamma_{13}^{\infty}$ values, indicating much better interactions with the cation, and are connected to the imidazolium ring in the cation as the increase in the alkyl chain, from $\mathrm{C}_{12}$ mim to $\mathrm{C}_{14} \mathrm{mim}$, weakens, in most cases, the solute/IL interactions. Despite their polar nature, alcohols and water do not present favorable interactions with the ILs investigated, unless in $\left[\mathrm{C}_{14} \mathrm{mim}\right]\left[\mathrm{BF}_{4}\right]$ at higher temperatures like already discussed above.

3.3. Thermodynamics of Interaction. In order to explore the collected experimental information, the thermodynamic functions at infinite dilution, namely the partial excess molar Gibbs energy, enthalpy, and entropy, were estimated from the $\gamma_{13}^{\infty}$ temperature dependency and are listed in Table S1 of the Supporting Information. It is important to highlight that for each IL, two temperatures were chosen in order to compare the two regions: liquid crystal and isotropic liquid (313.15 and $328.15 \mathrm{~K}$ for $\left[\mathrm{C}_{12} \mathrm{mim}\right]\left[\mathrm{BF}_{4}\right]$ and 358.15 and $403.15 \mathrm{~K}$ for $\left.\left[\mathrm{C}_{14} \mathrm{mim}\right]\left[\mathrm{BF}_{4}\right]\right)$.

A general overview of Table S1 and Figures S2 and S3 provides important information about the interactions between the solutes and the ILs. The changes at the smectic-isotropic transition temperatures indicate that the solutes are solvated in different ways in the two regions; changes in the slope are 

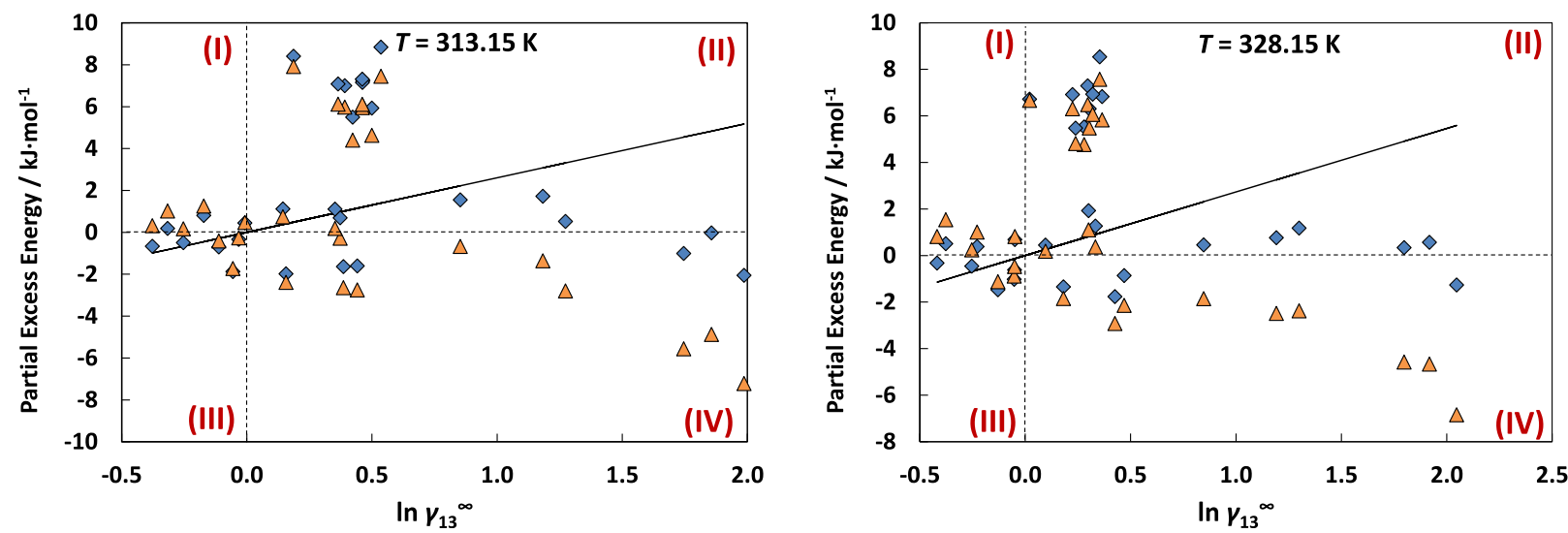

Figure 1. Partial molar excess energies as a function of $\gamma_{13}^{\infty}$ of the organic solutes studied in the ILC $\left[\mathrm{C}_{12} \mathrm{mim}\right]\left[\mathrm{BF}_{4}\right]$ at 313.15 and $328.15 \mathrm{~K}$. The line represents $\bar{G}_{\mathrm{m}}^{\mathrm{E}, \infty}$, and the symbols correspond to blue tilted square open, $\bar{H}_{\mathrm{m}}^{\mathrm{E}, \infty}$ and orange triangle up open, $T_{\text {ref }} \bar{S}_{\mathrm{m}}^{\mathrm{E}, \infty}$.
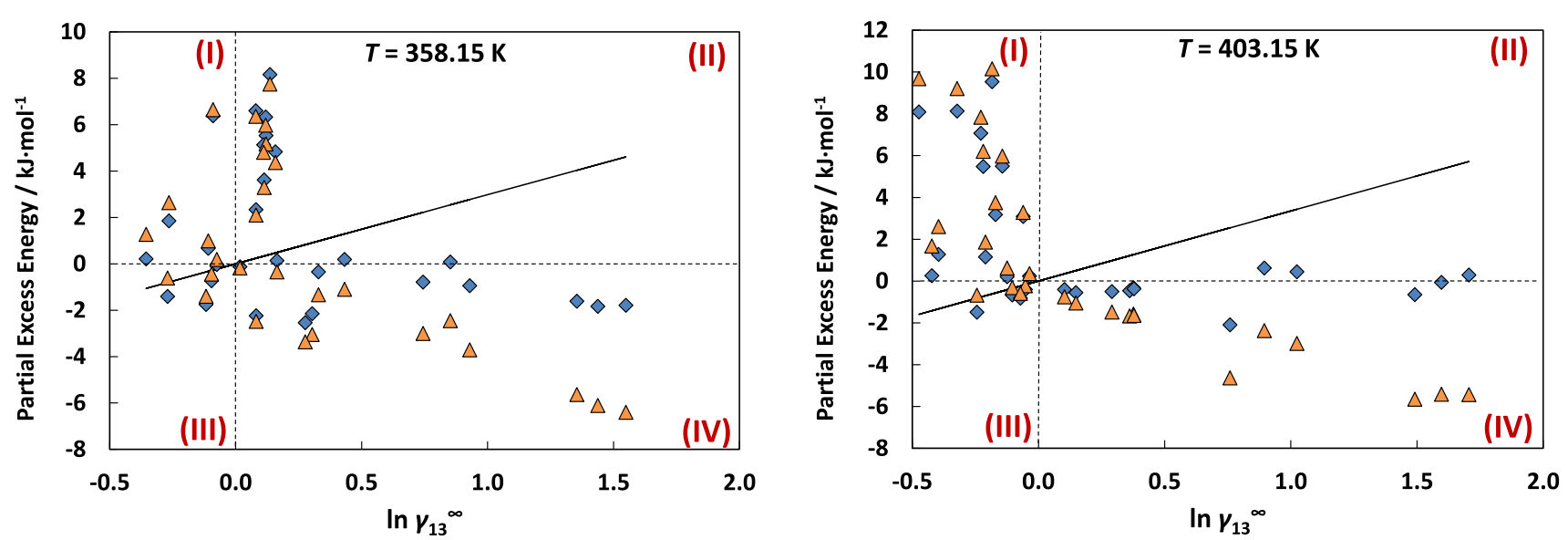

Figure 2. Partial molar excess energies as a function of $\gamma_{13}^{\infty}$ of the organic solutes studied in the ILC $\left[\mathrm{C}_{14} \mathrm{mim}\right]\left[\mathrm{BF}_{4}\right]$ at 358.15 and $403.15 \mathrm{~K}$. The line represents $\bar{G}_{\mathrm{m}}^{\mathrm{E}, \infty}$ and the symbols correspond to blue tilted square open, $\bar{H}_{\mathrm{m}}^{\mathrm{E}, \infty}$ and orange triangle square open, $T_{\text {ref }} \bar{S}_{\mathrm{m}}^{\mathrm{E}, \infty}$.

related to the enthalpic term, while changes in the intercept are related to the entropic term. In particular, for $\left[\mathrm{C}_{14} \mathrm{mim}\right]\left[\mathrm{BF}_{4}\right]$, changing from a smectic to an isotropic phase, there is an increase in the excess partial enthalpy and entropy at infinite dilution for alkanes, aromatics, water, and primary alcohols, while for esters and secondary or tertiary alcohols, both properties decrease, underlining significant differences in solvation. Moreover, it must be highlighted here that for both ILs, $\bar{H}_{\mathrm{m}}^{\mathrm{E}, \infty}$ for alcohols (water, acetone, and acetonitrile) is always positive, indicating endothermic interactions, while for other families of compounds, an exothermic behavior can be generally observed. Regarding the partial molar excess entropy values, Table S1 shows always positive values for alcohols, water, acetone, acetonitrile, and pyridine, and mostly negative for the remaining solutes. Thus, both scenarios indicate that the interaction of the solutes with the ILs investigated may be thermodynamically favored depending on the temperature. The partial excess molar Gibbs energy presents positive values for almost all solutes. The few exceptions are THF, dioxane, benzene, and more markedly acetone, acetonitrile, pyridine, and thiophene, indicating stronger interactions with oxygen, nitrogen, or sulfur atoms with the ILs combined with a structural cyclic effect. In the literature, for liquid crystals, it was reported that the ordered mesophases are stabilized by the enthalpic part, while the orientational entropy favors the isotropic state, ${ }^{32}$ but in terms of the interactions with the solutes, excepting alcohols and water, where the enthalpic and entropic contributions are very similar, for all other solutes the entropic term is dominant.

Figures 1 and 2 relate the activity coefficients at infinite dilution with the partial molar excess properties at two temperatures for each IL. Four different areas can be distinguished. In area (I), $\bar{G}_{\mathrm{m}}^{\mathrm{E}, \infty}$ is negative, and $\bar{H}_{\mathrm{m}}^{\mathrm{E}, \infty}$ and $\bar{S}_{\mathrm{m}}^{\mathrm{E}, \infty}$ are both positive, indicating a dominant entropic effect. Interestingly, as can be easily seen in Figure 2, for $\left[\mathrm{C}_{14} \mathrm{mim}\right]\left[\mathrm{BF}_{4}\right]$, a significant number of solutes (alcohols and water) move from region II to region I, when changing from the smectic to the isotropic phase. In area (II), positive deviations from ideality are also observed while still maintaining as positive both $\bar{S}_{\mathrm{m}}^{\mathrm{E}, \infty}$ and $\bar{H}_{\mathrm{m}}^{\mathrm{E}, \infty}$, suggesting a dominant enthalpic effect, even if similar absolute values of the enthalpic and entropic contributions are observed. Considering the alkanes and aromatics (except benzene), there are positive deviations from ideality, which are generally governed by an unfavorable entropic interaction, as $\bar{S}_{\mathrm{m}}^{\mathrm{E}, \infty}$ is always negative, corresponding often to area (IV). Finally, the polar aprotic solutes present a more complex distribution. As already mentioned, the interactions of these solutes with the ILs are always favorable, but while THF and thiophene fall in area (III), where both $\bar{S}_{\mathrm{m}}^{\mathrm{E}, \infty}$ and $\bar{H}_{\mathrm{m}}^{\mathrm{E}, \infty}$ are negative and so there is a dominant enthalpic effect, acetone and acetonitrile fall in area (I), and pyridine and 1,4-dioxane present undefined patterns between both ILs. 
3.4. Effect of the Cation Alkyl Chain Length. Studies on activity coefficients at infinite dilution have been reported for ILs with the same anion and 1-alkyl-3-methylimidazoliumbased cations. Data of some standard organic solutes were compiled and are presented in Figure 3 (listed in Table S2) at

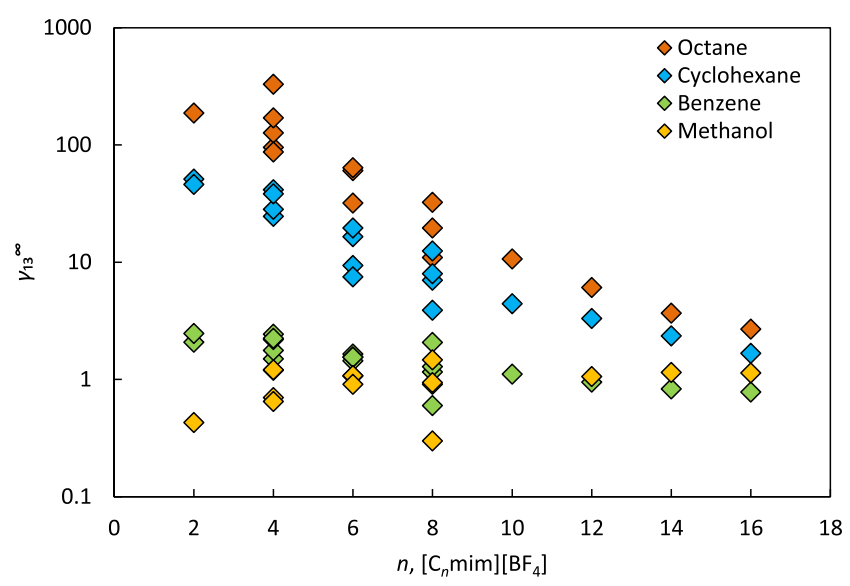

Figure 3. Effect of the cation alkyl chain on the activity coefficients at infinite dilution for some selected solvents at $323.15 \mathrm{~K}$ (references are available in Table S2).

$323.15 \mathrm{~K}$. This temperature was chosen since it is the most common for the data available in the literature. At this temperature, $\left[\mathrm{C}_{12} \mathrm{mim}\right]\left[\mathrm{BF}_{4}\right]$ is in the liquid state and $\left[\mathrm{C}_{14} \mathrm{mim}\right]\left[\mathrm{BF}_{4}\right]$ in the liquid crystal phase.

Figure 3 shows that, in general, the increasing of the alkyl chain length on the cation decreases the $\gamma_{13}^{\infty}$ for octane, cyclohexane, and benzene, highlighting the importance of the cation interactions with these solutes. This effect is more pronounced for octane, the less polar solute, confirming the foreseen dispersive interactions with the nonpolar solvent. Due to the polar character of methanol, the effect is the opposite; the increase of the alkyl chain length on the cation leads to a slight increase of $\gamma_{13}^{\infty}$.

3.5. Gas-Liquid Partition Coefficients. Gas-liquid partition coefficients, $K_{\mathrm{L}}$, are related to the distribution of individual compounds between different organic phases and water or air, which makes them very attractive in chemical engineering and environmental modeling areas. Moreover, the solubility of selected substances can be predicted from them. Here, $K_{\mathrm{L}}$ values were calculated through eq 7 using experimental values of retention times and IL densities.

Densities of the pure $\left[\mathrm{C}_{12} \mathrm{mim}\right]\left[\mathrm{BF}_{4}\right]$ were reported by us before. ${ }^{13}$ For $\left[\mathrm{C}_{14} \mathrm{mim}\right]\left[\mathrm{BF}_{4}\right]$, the densities were estimated in the temperature range (318.14-363.14) $\mathrm{K}$ using the experimental data of Montalbán et al., ${ }^{33}$ assuming that the volumes of the IL ions behave as an "ideal" mixture allowing the determination of their molar volume, and consequently the density, according to the approach proposed initially by Rebelo et al. $^{34}$ To the best of our knowledge, no density data are available for comparison in the open literature. From the results displayed in Table S3, it may be observed that by adding two methylene groups $\left(-\mathrm{CH}_{2}-\right)$ to the cation alkyl chain, the density decreases as $\mathrm{CH}_{2}$ is less dense than the imidazolium ring. Using the same approach, the average relative deviation obtained for $\left[\mathrm{C}_{12} \mathrm{mim}\right]\left[\mathrm{BF}_{4}\right]$ (compared to the experimental data measured in this work) was $0.21 \%$.

Results of $K_{\mathrm{L}}$ are listed in Table S4 of the Supporting Information, and comparison for liquid crystal and liquid regions is presented in Figure 4. For most of the solutes, $K_{\mathrm{L}}$ increases with the number of carbon atoms in the solute and decreases with increasing temperature. A higher $K_{\mathrm{L}}$ reflects a greater difficulty in the transition between the gas and the liquid. Concerning the solvents investigated here, the highest value is observed for decane $(3101.83$ at $T=308.15 \mathrm{~K}$ and 671.02 at $T=343.15 \mathrm{~K}$ for $\left[\mathrm{C}_{12} \mathrm{mim}\right]\left[\mathrm{BF}_{4}\right]$ and $\left[\mathrm{C}_{14} \mathrm{mim}\right]$ $\left[\mathrm{BF}_{4}\right]$, respectively), whereas the lowest is observed for diethyl ether, indicating the possibility of its separation from a mixture of other organic compounds.

3.6. Selectivities and Capacities. A proper solvent should possess both a high selectivity $\left(S_{i j}^{\infty}\right)$ and a high capacity $\left(k_{j}^{\infty}\right)$ for the components to be separated. In this work, these parameters were calculated through the equations presented in Section 2.3 and used to evaluate the ILs' performance as entrainers for the separations of octane/benzene and cyclohexane/benzene. The results obtained are displayed in Table 4, along with other ILs from the literature presenting the same anion in imidazolium-based ILs as well as those investigated by

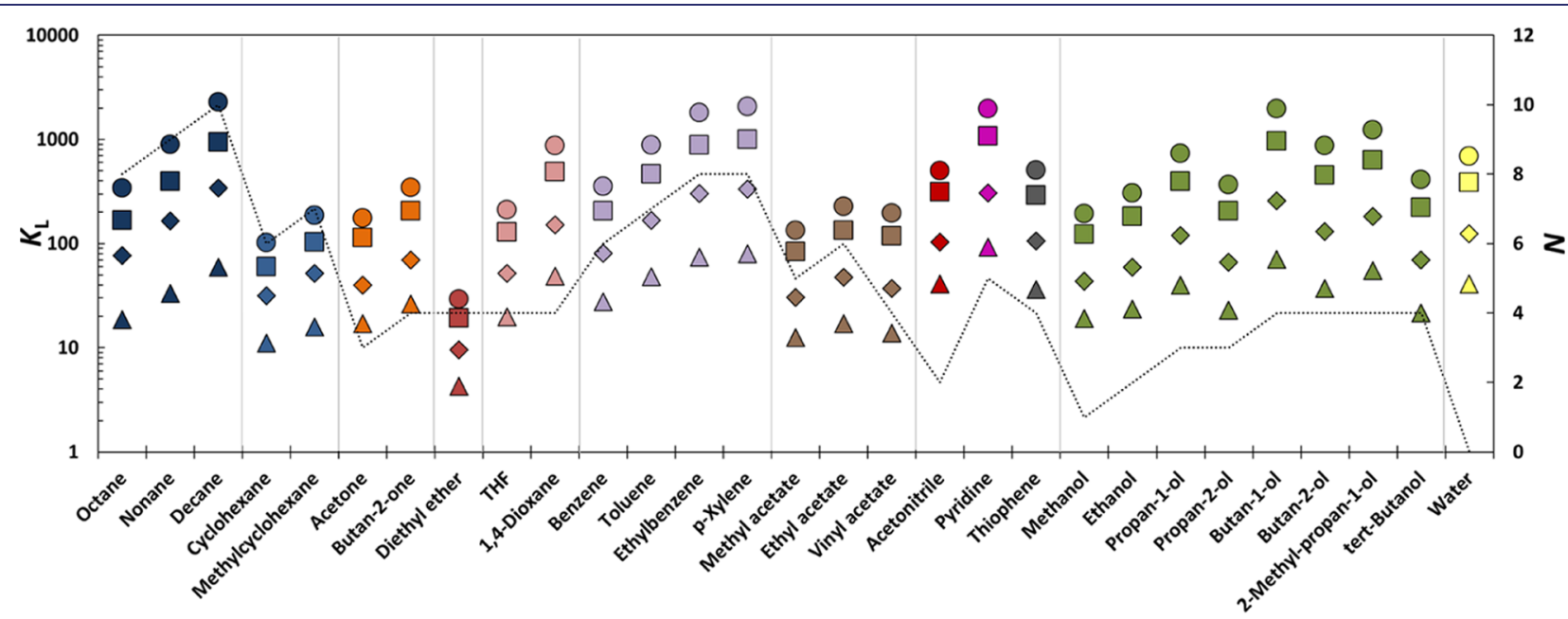

Figure 4. Experimental gas-liquid partition coefficients, $K_{\mathrm{L}}$, for organic solutes and water in the ILs studied. $\bigcirc$, $\left[\mathrm{C}_{12} \mathrm{mim}\right]\left[\mathrm{BF}_{4}\right]$ at $313.15 \mathrm{~K}$; $\square$, $\left[\mathrm{C}_{12} \mathrm{mim}\right]\left[\mathrm{BF}_{4}\right]$ at $328.15 \mathrm{~K} ;(\mathrm{b}) \diamond,\left[\mathrm{C}_{14} \mathrm{mim}\right]\left[\mathrm{BF}_{4}\right]$ at $358.15 \mathrm{~K} ; \triangle,\left[\mathrm{C}_{14} \mathrm{mim}\right]\left[\mathrm{BF}_{4}\right]$ at $403.15 \mathrm{~K}$. The dotted line represents the number of carbons in the solutes' structure, $N$. Symbols with the same color correspond to solutes within the same chemical family. 
Table 4. Selectivities $\left(S_{i j}^{\infty}\right)$ and Capacities $\left(k_{j}^{\infty}\right)$ at Infinite Dilution for Different Separation Problems at $323.15 \mathrm{~K}$

\begin{tabular}{|c|c|c|c|c|c|}
\hline ILs & & $S^{\infty}$ octane/benzene & $S^{\infty}$ cyclohexane/benzene & $K_{\text {benzene }}^{\infty}$ & references \\
\hline \multirow[t]{2}{*}[\mathrm{C}_{2}\mathrm{mim}]{$\left[\mathrm{BF}_{4}\right]$} & $a$ & 90.37 & 24.70 & 0.48 & 35 \\
\hline & $a$ & & 18.73 & 0.41 & 27 \\
\hline \multirow[t]{3}{*}[\mathrm{C}_{4}\mathrm{mim}]{$\left[\mathrm{BF}_{4}\right]$} & $a$ & 63.67 & 16.47 & 0.67 & 36 \\
\hline & $a$ & 71.04 & 16 & 0.56 & 37 \\
\hline & $b$ & 151.97 & 19.34 & 0.46 & 38 \\
\hline \multirow[t]{2}{*}[\mathrm{C}_{6}\mathrm{mim}]{$\left[\mathrm{BF}_{4}\right]$} & $a$ & & 8.67 & 0.57 & 27 \\
\hline & $a$ & 33.68 & 10.84 & 1.05 & 39 \\
\hline$\left[\mathrm{C}_{6} \mathrm{mmim}\right]\left[\mathrm{BF}_{4}\right]$ & $a$ & 41.33 & 12.65 & 0.65 & 40 \\
\hline \multirow[t]{3}{*}[\mathrm{C}_{8}\mathrm{mim}]{$\left[\mathrm{BF}_{4}\right]$} & $a$ & & 6.18 & 0.78 & 27 \\
\hline & $a$ & 18.33 & 6.50 & 1.67 & 36 \\
\hline & $b$ & 19.60 & 6.06 & 0.86 & 41 \\
\hline$\left[\mathrm{C}_{8} \mathrm{mmim}\right]\left[\mathrm{BF}_{4}\right]$ & $a$ & 15.71 & 6.02 & 0.48 & 42 \\
\hline$\left[\mathrm{C}_{12} \mathrm{mim}\right]\left[\mathrm{BF}_{4}\right]$ & $a$ & 6.42 & 3.51 & 1.05 & this work \\
\hline$\left[\mathrm{C}_{14} \mathrm{mim}\right]\left[\mathrm{BF}_{4}\right]$ & $c$ & 4.42 & 2.82 & 1.20 & this work \\
\hline$\left[\mathrm{C}_{16} \mathrm{mim}\right]\left[\mathrm{BF}_{4}\right]$ & $a$ & 3.45 & 2.14 & 1.28 & 43 \\
\hline$\left[\mathrm{C}_{4} \operatorname{mim}\right] \mathrm{Cl}$ & $c$ & 100.52 & 15.95 & 0.24 & 15 \\
\hline$\left[\mathrm{C}_{4} \mathrm{mim}\right]\left[\mathrm{CH}_{3} \mathrm{SO}_{3}\right]$ & $c$ & 71.45 & 13.93 & 0.38 & 15 \\
\hline$\left[\mathrm{C}_{4} \mathrm{mim}\right][\mathrm{OAc}]$ & $c$ & 36.56 & 8.62 & 0.39 & 17 \\
\hline$\left[\mathrm{C}_{4} \mathrm{mim}\right]\left[\left(\mathrm{CH}_{3}\right)_{2} \mathrm{PO}_{4}\right]$ & $c$ & 26.92 & 6.68 & 0.51 & 15 \\
\hline \multicolumn{6}{|c|}{ Other Solvents } \\
\hline sulfolane & $c$ & 37.42 & & 0.43 & 44 \\
\hline NMP & $a$ & 6.51 & & 0.95 & 45 \\
\hline
\end{tabular}

${ }^{a}$ Experimental value. ${ }^{b}$ Interpolated value. ${ }^{c}$ Extrapolated value.

us before. ${ }^{15}$ The common used industrial solvents $N$-methyl-2pyrrolidinone (NMP) and sulfolane are also presented for comparison.

Considering only the tetrafluoroborate-based ILs, Table 4 shows that high selectivities are obtained using cations with short alkyl chain lengths, while high capacities are achieved with large alkyl chain lengths. In both separation problems, despite the low capacity values, the $\mathrm{IL}\left[\mathrm{C}_{2} \mathrm{mim}\right]\left[\mathrm{BF}_{4}\right]$ is the most adequate. Moreover, the separation problem octane/ benzene is easier to carry out, presenting higher selectivities than cyclohexane/benzene. Both findings are in agreement with our past findings, ${ }^{15}$ where the IL $\left[\mathrm{C}_{4}\right.$ mim $] \mathrm{Cl}$ was selected as the most appropriate solvent for the separation of octane/ benzene. NMP and sulfolane, the common solvents used in industries, present lower values of selectivities than most of the ILs studied here.

\section{CONCLUSIONS}

Activity coefficients at infinite dilution for a variety of solutes in the ILs $\left[\mathrm{C}_{12} \mathrm{mim}\right]\left[\mathrm{BF}_{4}\right]$ and $\left[\mathrm{C}_{14} \mathrm{mim}\right]\left[\mathrm{BF}_{4}\right]$ were measured using the GLC technique at different temperatures. Polar aprotic solvents show higher affinity to the ILs studied, while for polar protic solvents such as alcohols and water, the interaction is only favorable at a higher temperature. Alkane and alkylbenzene solvation in the ILs, occurring in the apolar moieties of the cation, presents positive deviations from ideality that diminishes on increasing the alkyl chain length. Concerning the two aggregation states (smectic or isotropic liquid) of both ILs, a discontinuity in the representation of the natural logarithm of $\gamma_{13}^{\infty}$ with the reciprocal temperature is observed, particularly for $\left[\mathrm{C}_{14} \mathrm{mim}\right]\left[\mathrm{BF}_{4}\right]$. In such cases, there is an increase in the excess partial enthalpy and entropy at infinite dilution for alkanes, aromatics, water, and primary alcohols, while for esters and secondary or tertiary alcohols, both properties decrease, underlining the differences in the solvation when changing from the smectic to the isotropic liquid. Regarding the separation problems evaluated, to achieve the maximum separation efficiency, imidazolium cations with shorter alkyl chain lengths such as $\left[\mathrm{C}_{2} \mathrm{mim}\right]\left[\mathrm{BF}_{4}\right]$ should be used, whereas higher capacities require larger alkyl chain lengths.

\section{ASSOCIATED CONTENT}

\section{st Supporting Information}

The Supporting Information is available free of charge at https://pubs.acs.org/doi/10.1021/acs.jced.1c00182.

DSC thermogram for $\left[\mathrm{C}_{14} \mathrm{mim}\right]\left[\mathrm{BF}_{4}\right]$; representation of $\ln \gamma_{13}^{\infty}$ of organic solutes and water as a function of the reciprocal temperature for $\left[\mathrm{C}_{12} \mathrm{mim}\right]\left[\mathrm{BF}_{4}\right]$ and $\left[\mathrm{C}_{14} \mathrm{mim}\right]\left[\mathrm{BF}_{4}\right]$; excess partial molar properties of organic solutes and water in the ILCs; comparison between the $\gamma_{13}^{\infty}$ of some organic solutes in $\left[\mathrm{C}_{n} \mathrm{mim}\right]$ $\left[\mathrm{BF}_{4}\right]$, with $\mathrm{n}$ ranging from 2 to 16 ; experimental and predicted densities for the ILCs under study; and experimental gas-liquid partition coefficients for organic solutes and water at different temperatures derived from the chromatographic experiments (PDF)

\section{AUTHOR INFORMATION}

\section{Corresponding Author}

Simão P. Pinho - Mountain Research Center-CIMO, Polytechnic Institute of Bragança, 5301-855 Bragança, Portugal; (1) orcid.org/0000-0002-9211-857X; Phone: +351 273303086; Email: spinho@ipb.pt; Fax: +351273313051

\section{Authors}

Mónia A. R. Martins - Mountain Research Center-CIMO, Polytechnic Institute of Bragança, 5301-855 Bragança, Portugal; CICECO-Aveiro Institute of Materials, Department of Chemistry, University of Aveiro, 3810-193

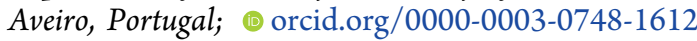


Sérgio M. Vilas-Boas - Mountain Research Center-CIMO, Polytechnic Institute of Bragança, 5301-855 Bragança, Portugal; CICECO-Aveiro Institute of Materials, Department of Chemistry, University of Aveiro, 3810-193 Aveiro, Portugal

Isabella Weber Cordova - Mountain Research CenterCIMO, Polytechnic Institute of Bragança, 5301-855 Bragança, Portugal

Pedro J. Carvalho - CICECO-Aveiro Institute of Materials, Department of Chemistry, University of Aveiro, 3810-193 Aveiro, Portugal; $\odot$ orcid.org/0000-0002-1943-0006

Urszula Domańska - Industrial Chemistry Research Institute, 01-793 Warsaw, Poland; @ orcid.org/0000-0001-50345873

Olga Ferreira - Mountain Research Center-CIMO, Polytechnic Institute of Bragança, 5301-855 Bragança, Portugal; @ orcid.org/0000-0001-8414-3479

João A. P. Coutinho - CICECO-Aveiro Institute of Materials, Department of Chemistry, University of Aveiro, 3810-193 Aveiro, Portugal; ๑ orcid.org/0000-0002-3841$743 \mathrm{X}$

Complete contact information is available at: https://pubs.acs.org/10.1021/acs.jced.1c00182

\section{Notes}

The authors declare no competing financial interest.

\section{ACKNOWLEDGMENTS}

This work was developed within the scope of the project CICECO-Aveiro Institute of Materials, UIDB/50011/2020 and UIDP/50011/2020 and CIMO-Mountain Research Center, UIDB/00690/2020, financed by national funds through the Portuguese Foundation for Science and Technology/MCTES. M.A.R.M. acknowledges financial support from NORTE-01-0145-FEDER-000006-funded by NORTE2020 through PT2020 and ERDF. S.M.V.B. acknowledges FCT for his Ph.D. grant SFRH/BD/138149/2018. P.J.C. acknowledges FCT for his contract under the Investigator FCT 2015 contract number IF/00758/2015.

\section{REFERENCES}

(1) MacFarlane, D. R.; Seddon, K. R. Ionic Liquids-Progress on the Fundamental Issues. Aust. J. Chem. 2007, 60, 3-5.

(2) Canongia Lopes, J. N. A.; Pádua, A. A. H. Nanostructural Organization in Ionic Liquids. J. Phys. Chem. B 2006, 110, 33303335.

(3) Green Industrial Applications of Ionic Liquids, 1st ed.; Rogers, R. D., Seddon, K. R., Volkov, S., Eds.; Springer Netherlands: Dordrecht, 2002.

(4) Binnemans, K. Ionic Liquid Crystals. Chem. Rev. 2005, 105, 4148-4204.

(5) Goossens, K.; Lava, K.; Bielawski, C. W.; Binnemans, K. Ionic Liquid Crystals: Versatile Materials. Chem. Rev. 2016, 116, 46434807.

(6) Kondrat, S.; Bier, M.; Harnau, L. Phase Behavior of Ionic Liquid Crystals. J. Chem. Phys. 2010, 132, 184901.

(7) Jeknavorian, A. A.; Barrett, P.; Watterson, A. C.; Barry, E. F. Thermodynamic Study of a Liquid Crystal as a Liquid Phase in GasLiquid Chromatography II. A Cholesteric Liquid Crystal. J. Chromatogr. A 1975, 107, 317-325.

(8) Oweimreen, G. A. Thermodynamic Data for Nonmesomorphic Solutes at Infinite Dilution in the Nematic and Isotropic Phases of Hexylcyanobiphenyl. J. Solution Chem. 1982, 11, 105-118.
(9) Gidley, M. A.; Stubley, D. Activity Coefficients at Infinite Dilution of Solutes in Liquid-Crystalline Solvents. J. Chem. Thermodyn. 1986, 18, 595-600.

(10) Oweimreen, G. A.; Al-Tawfiq, A. M. Thermodynamics of Solution of Nonmesomorphic Solutes at Infinite Dilution in the Isotropic and Nematic Phases of P-Cyanophenyl p-n-Alkylbenzoates. J. Chem. Eng. Data 1997, 42, 996-1003.

(11) Price, G. J.; Shillcock, I. M. Inverse Gas Chromatography Study of the Thermodynamic Behaviour of Thermotropic Low Molar Mass and Polymeric Liquid Crystals. Phys. Chem. Chem. Phys. 2002, 4, 5307-5316.

(12) Oweimreen, G. A. Enthalpy-Entropy Compensation and Solubility Parameters for Solutions of Nonmesomorphic Solutes in the Smectic-A, Nematic and Isotropic Phases of the Liquid Crystal pn-Octyl-P'-Cyanobiphenyl. J. Solution Chem. 2011, 40, 79-92.

(13) Martins, M. A. R.; Carvalho, P. J.; Alves, D.; Dariva, C.; Costa, M. C.; Ferreira, R. A. S.; André, P. S.; Morgado, P.; Pinho, S. P.; Filipe, E. J. M.; et al. Surface Crystallization of Ionic Liquid Crystals. Phys. Chem. Chem. Phys. 2019, 21, 17792-17800.

(14) Domańska, U.; Lukoshko, E. V.; Wlazło, M. Measurements of Activity Coefficients at Infinite Dilution for Organic Solutes and Water in the Ionic Liquid 1-Hexyl-3-Methylimidazolium Tetracyanoborate. J. Chem. Thermodyn. 2012, 47, 389-396.

(15) Martins, M. A. R.; Coutinho, J. A. P.; Pinho, S. P.; Domańska, U. Measurements of Activity Coefficients at Infinite Dilution of Organic Solutes and Water on Polar Imidazolium-Based Ionic Liquids. J. Chem. Thermodyn. 2015, 91, 194-203.

(16) Martins, M. A. R.; Domańska, U.; Schröder, B.; Coutinho, J. A. P.; Pinho, S. P. Selection of Ionic Liquids to Be Used as Separation Agents for Terpenes and Terpenoids. ACS Sustain. Chem. Eng. 2016, 4, 548-556.

(17) Vilas-Boas, S. M.; Teixeira, G.; Rosini, S.; Martins, M. A. R.; Gaschi, P. S.; Coutinho, J. A. P.; Ferreira, O.; Pinho, S. P. Ionic Liquids as Entrainers for Terpenes Fractionation and Other Relevant Separation Problems. J. Mol. Liq. 2021, 323, 114647.

(18) Cruickshank, A. J. B.; Windsor, M. L.; Young, C. L. The Use of Gas-Liquid Chromatography to Determine Activity Coefficients and Second Virial Coefficients of Mixtures. I. Theory and Verification of Method of Data Analysis. Proc. R. Soc. A 1966, 295, 259-270.

(19) Everett, D. H. Effect of Gas Imperfection on G.L.C. Measurements: A Refined Method for Determining Activity Coefficients and Second Virial Coefficients. Faraday Soc. Trans. 1965, 61, 1637-1645.

(20) Cruickshank, A. J. B.; Gainey, B. W.; Hicks, C. P.; Letcher, T. M.; Moody, R. W.; Young, C. L. Gas-Liquid Chromatographic Determination of Cross-Term Second Virial Coefficients Using Glycerol. Benzene + Nitrogen and Benzene + Carbon Dioxide at $50^{\circ}$ C. Faraday Soc. Trans. 1969, 65, 1014-1031.

(21) Domańska, U.; Marciniak, A. Measurements of Activity Coefficients at Infinite Dilution of Aromatic and Aliphatic Hydrocarbons, Alcohols, and Water in the New Ionic Liquid [EMIM][SCN] Using GLC. J. Chem. Thermodyn. 2008, 40, 860-866.

(22) Domańska, U.; Marciniak, A. Activity Coefficients at Infinite Dilution Measurements for Organic Solutes and Water in the Ionic Liquid 1-Ethyl-3-Methylimidazolium Trifluoroacetate. J. Phys. Chem. B 2007, 111, 11984.

(23) Kolbe, B.; Gmehling, J.; Onken, U. Auswahl von Lösungsmitteln Für Die Extraktiv-Rektifikation Mittels Vorausberechneter Gleichgewichtsdaten. Berichte der Bunsengesellschaft für Phys. Chemie 1979, 83, 1133-1136.

(24) Holbrey, J. D.; Seddon, K. R. The Phase Behaviour of 1-Alkyl3-Methylimidazolium Tetrafluoroborates; Ionic Liquids and Ionic Liquid Crystals. J. Chem. Soc., Dalton Trans. 1999, 13, 2133-2140.

(25) Nozaki, Y.; Yamaguchi, K.; Tomida, K.; Taniguchi, N.; Hara, H.; Takikawa, Y.; Sadakane, K.; Nakamura, K.; Konishi, T.; Fukao, K. Phase Transition and Dynamics in Imidazolium-Based Ionic Liquid Crystals through a Metastable Highly Ordered Smectic Phase. J. Phys. Chem. B 2016, 120, 5291-5300. 
(26) Cláudio, A. F. M.; Swift, L.; Hallett, J. P.; Welton, T.; Coutinho, J. A. P.; Freire, M. G. Extended Scale for the Hydrogen-Bond Basicity of Ionic Liquids. Phys. Chem. Chem. Phys. 2014, 16, 6593-6601.

(27) Foco, G. M.; Bottini, S. B.; Quezada, N.; de la Fuente, J. C.; Peters, C. J. Activity Coefficients at Infinite Dilution in 1-Alkyl-3Methylimidazolium Tetrafluoroborate Ionic Liquids. J. Chem. Eng. Data 2006, 51, 1088-1091.

(28) Gritti, F.; Félix, G.; Achard, M.-F.; Hardouin, F. Investigation of the Nematic-Isotropic Transition of a Liquid Crystalline Polymer and Determination of Molecular Diffusion Coefficients Using Gas Chromatography. J. Chromatogr. A 2000, 893, 359-366.

(29) Baniceru, M.; Radu, S. Thermodynamic Studies on Infinitely Dilute Solutions of Xylenes and Ethyltoluenes on 3,4'-Dimethyl-4[(4-Chlorobenzyl)Oxy]Azobenzene Liquid Crystal. Fluid Phase Equilib. 2000, 167, 243-251.

(30) Sesigur, F.; Sakar, D.; Yasa-Sahin, O.; Ocak, H.; Cankurtaran, O.; Bilgin-Eran, B.; Karaman, F. Thermodynamic and Surface Characterisation of (S)-5-Dodecycloxy-2-[[[4-(2-Methylbutoxy) Phenyl]Imino]Metheyl]Phenol Thermotropic Liquid Crystal by Inverse Gas Chromatography. Liq. Cryst. 2012, 39, 87-97.

(31) Vaz, I. C. M.; Bastos, M.; Bernardes, C. E. S.; Canongia Lopes, J. N.; Santos, L. M. N. B. F. Solvation of Alcohols in Ionic LiquidsUnderstanding the Effect of the Anion and Cation. Phys. Chem. Chem. Phys. 2018, 20, 2536-2548.

(32) Andrienko, D. Introduction to Liquid Crystals. J. Mol. Liq. 2018, 267, 520-541.

(33) Montalbán, M. G.; Bolívar, C. L.; Díaz Baños, F. G.; Víllora, G. Effect of Temperature, Anion, and Alkyl Chain Length on the Density and Refractive Index of 1-Alkyl-3-Methylimidazolium-Based Ionic Liquids. J. Chem. Eng. Data 2015, 60, 1986-1996.

(34) Rebelo, L. P. N.; Najdanovic-Visak, V.; de Azevedo, R. G.; Esperança, J. M. S. S.; da Ponte, M. N.; Guedes, H. J. R.; Visak, Z. P.; Sousa, H. C. de.; Szydlowski, J.; Lopes, J. N. C. Ionic Liquids III A: Fundamentals, Progress, Challenges, and Ppportunities; Rogers, R. D., Seddon, K. R., Eds.; ACS Symposium Series; American Chemical Society: Washington, DC, 2005; Vol. 901.

(35) Ge, M.-L.; Wang, L.-S.; Wu, J.-S.; Zhou, Q. Activity Coefficients at Infinite Dilution of Organic Solutes in 1-Ethyl-3Methylimidazolium Tetrafluoroborate Using Gas-Liquid Chromatography. J. Chem. Eng. Data 2008, 53, 1970-1974.

(36) Zhang, J.; Zhang, Q.; Qiao, B.; Deng, Y. Solubilities of the Gaseous and Liquid Solutes and Their Thermodynamics of Solubilization in the Novel Room-Temperature Ionic Liquids at Infinite Dilution by Gas Chromatography. J. Chem. Eng. Data 2007, 52, 2277-2283.

(37) Zhou, Q.; Wang, L.-S. Activity Coefficients at Infinite Dilution of Alkanes, Alkenes, and Alkyl Benzenes in 1-Butyl-3-Methylimidazolium Tetrafluoroborate Using Gas-liquid Chromatography. J. Chem. Eng. Data 2006, 51, 1698-1701.

(38) Revelli, A.-L.; Mutelet, F.; Turmine, M.; Solimando, R.; Jaubert, J.-N. Activity Coefficients at Infinite Dilution of Organic Compounds in 1-Butyl-3-Methylimidazolium Tetrafluoroborate Using Inverse Gas Chromatography. J. Chem. Eng. Data 2009, 54, 90-101.

(39) Letcher, T. M.; Soko, B.; Reddy, P.; Deenadayalu, N. Determination of Activity Coefficients at Infinite Dilution of Solutes in the Ionic Liquid 1-Hexyl-3-Methylimidazolium Tetrafluoroborate Gsing Gas-liquid Chromatography at the Temperatures $298.15 \mathrm{~K}$ and 323.15 K. J. Chem. Eng. Data 2003, 48, 1587-1590.

(40) He, Z.-Z.; Zhai, J.-Y.; Mu, H.; Zhang, M.; Yu, Y.; Zheng, J.-L.; Jiao, Y.-H.; Ge, M.-L.; Wu, R.-X. Thermodynamics and Selectivity of Separation Based on Activity Coefficients at Infinite Dilution of Various Solutes in Ionic Liquid [HMMIM][BF4]. J. Chem. Thermodyn. 2018, 125, 142-148.

(41) Heintz, A.; Verevkin, S. P. Thermodynamic Properties of Mixtures Containing Ionic Liquids. 6. Activity Coefficients at Infinite Dilution of Hydrocarbons, Alcohols, Esters, and Aldehydes in 1Methyl-3-Octyl-Imidazolium Tetrafluoroborate Using Gas-liquid Chromatography. J. Chem. Eng. Data 2005, 50, 1515-1519.
(42) He, Z.-Z.; Miao-Zhang; Ge, M.-L.; Jiao, Y.-H.; Zhao-Mu; Yi, Y.F.; Ding, F.-C. Separation of Binary Mixtures Based on Gamma Infinity Data Using [OMMIM][BF4] Ionic Liquid and Modelling of Thermodynamic Functions. J. Chem. Thermodyn. 2019, 129, 22-29.

(43) Mutelet, F.; Jaubert, J.-N. Measurement of Activity Coefficients at Infinite Dilution in 1-Hexadecyl-3-Methylimidazolium Tetrafluoroborate Ionic Liquid. J. Chem. Thermodyn. 2007, 39, 1144-1150.

(44) Yu, Y.-X.; Gong, Q.; Huang, L.-L. Measurement of Activity Coefficient at Infinite Dilution of Hydrocarbons in Sulfolane Using Gas-Liquid Chromatography. J. Chem. Eng. Data 2007, 52, 14591463.

(45) Krummen, M.; Gruber, D.; Gmehling, J. Measurement of Activity Coefficients at Infinite Dilution in Solvent Mixtures Using the Dilutor Technique. Ind. Eng. Chem. Res. 2000, 39, 2114-2123. 